\title{
Lewinskya laevigata (J.E. Zetterst.) F. Lara et al. (Bryophyta, Orthotrichaceae) en Sierra Nevada (España)
}

Juan Guerra

Departamento de Biología Vegetal, Área de Botánica, Facultad de Biología, Universidad de Murcia, 30100 Murcia (España).

Correspondencia

J. Guerra

E-mail: jguerra@um.es

Recibido: 28 noviembre 2018

Aceptado: 21 enero 2019

Publicado on-line: 24 enero 2019

\section{Resumen}

Lewinskya laevigata (J.E. Zetterst.) F. Lara et al., un musgo árticoalpino, muy raro en el área mediterránea, se cita por segunda vez en la Península Ibérica. La muestra ha sido recolectada en los Peñones de San Francisco (Sierra Nevada, España).

Palabras clave: Musgos; Península Ibérica; Corología; Nueva cita.

\begin{abstract}
Lewinskya laevigata (J.E. Zetterst.) F. Lara et al. (Bryophyta, Orthotrichaceae) in Sierra Nevada (Spain)

Lewinskya laevigata (J.E. Zetterst.) F. Lara et al., an arctic-alpine moss, very rare in the Mediterranean area, is recorded for the second time in the Iberian Peninsula. The sample has been collected in the Peñones de San Francisco (Sierra Nevada, Spain).
\end{abstract}

Key words: Mosses; Iberian Peninsula; Chorology; New record.

\section{Introducción}

Lewinskya laevigata (J.E. Zetterst) F. Lara, Garilleti \& Goffinet (= Orthotrichum laevigatum J.E. Zetterst.) es una rara especie de musgo en el sur de Europa, generalmente saxícola y acidófila, que se conocía de la Península Ibérica, hasta el momento, de un área relativamente pequeña (Madrid, Rascafría, circo de Peñalara). Su presencia en esta localidad del Sistema Central, donde había sido recolectada en el transcurso de una excursión de la Sociedad Española de Briología en junio de 2012, fue puesta de manifiesto por Garilleti et al. (2014) y posteriormente por Lara \& Garilleti (2014).

$\mathrm{Su}$ distribución general comprende el oeste de Europa y Asia (Himalayas, áreas alpinas y subalpinas de Japón, Cáucaso, suroeste de China, montañas de Altai, sureste de Siberia) y oeste de Norteamérica (cf. Garilleti et al. 2014). Es, pues, una especie holártica que en Europa formaría parte del elemento corológico ártico-alpino; mayoritariamente extendido en Islandia, Suecia, Noruega, con algunas poblaciones en las montañas del sur de Europa, usualmente en los Alpes (Lewinsky 1993, Maier \& SchäferVerwimp 1999), aunque también se ha encontrado en Cerdeña (Lara et al. 2002) y los Balcanes (Blockeel 2010). En esta nota se da cuenta de su existencia en los Peñones de San Francisco, Sierra Nevada (Granada, España). Es sorprendente que haya permanecido desapercibida en una de las localidades más visitadas y recolectadas por briólogos de toda Europa.

Dentro del género Orthotrichum Hedw., la especie se encontraba ubicada en el subgénero 
Phaneroporum Delogne (cápsulas con estomas faneróporos, gonioautoico). Recientemente, ha sido combinada en el nuevo género Lewinskya (cf. Lara et al. 2016).

\section{Material estudiado}

España: Madrid, Rascafría, circo de Peñalara, $40^{\circ} 50^{\prime} 17.50^{\prime} \mathrm{N}, 03^{\circ} 57^{\prime} 26.10^{\prime \prime} \mathrm{W}, 2.050 \mathrm{msnm}$, 14/VI/2012, Brugués et al. (VAL 9955). Granada, Güejar-Sierra, Sierra Nevada, Peñones de San Francisco, $2.500 \mathrm{msnm}, 37^{\circ} 6^{\prime} \mathrm{N}, 3^{\circ} 23^{\prime} \mathrm{W}, 1 / \mathrm{VIII} /$ 2018, Guerra (MUB 57655) (Fig. 1).

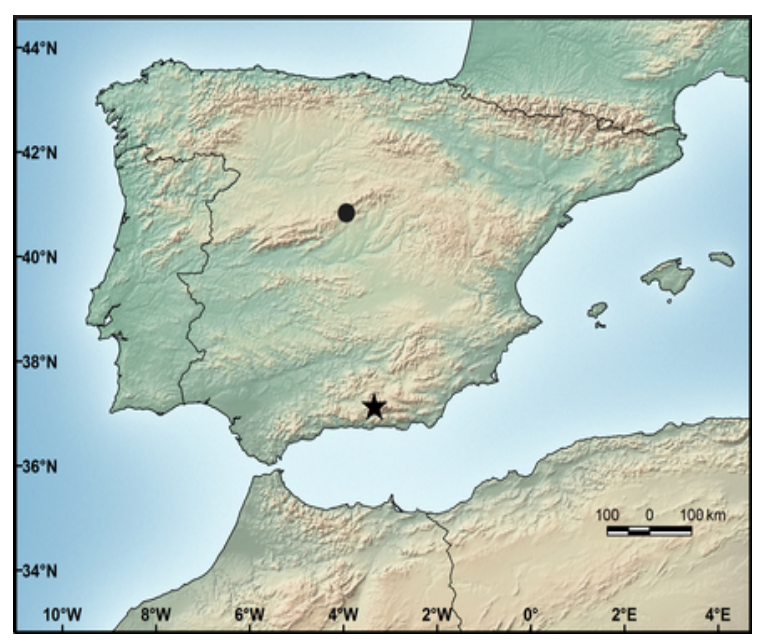

Figura 1. Distribución conocida de Lewinskya laevigata en la Península Ibérica. ( $\star$ ) Nueva cita.

Figure 1. Current distribution of Lewinskya laevigata in the Iberian Peninsula. ( $\star$ New record.

\section{Resultados}

Se trata de una especie relativamente fácil de identificar, incluso macroscópicamente. Se caracteriza por los filidios de adpresos a erectos en secos, de patentes a extendidos en húmedo, de lanceolados a oval-lanceolados, de ápice anchamente agudo a obtuso, incluso redondeado y márgenes de fuertemente recurvados a revolutos. Cápsulas largamente exertas, de urna estrechamente cilíndrica, de amarillenta a ligeramente pardusca, con el cuello corto que se adelgaza progresivamente hacia la seta, prácticamente lisa o con 8 costillas poco o nada prominentes, opérculo cónico. Los propágulos flageliformes descritos por Garilleti et al. (2014) no se han visto en la muestra del sur de España.

Posee células superiores y medias de la lámina de los filidios redondeadas a elípticas, con 1-3(4) papilas simples o ramificadas; células basales de la lámina rectangulares, de rectas a sinuosas o nodulosas, lisas. Exotecio con estomas faneróporos, numerosos (6-7) y situados en una amplia zona hacia la mitad de la urna, bandas exoteciales de poco diferenciadas a inconspicuas, con 3-5 hileras de células de paredes poco engrosadas. El exóstoma consiste en 8 pares de dientes amarillentos, erectos o extendidos, incluso en cápsulas viejas, que pueden escindirse en 16, en la superficie externa muy papilosos, hacia la base con trabéculas de grosor variable (en los ejemplares de Sierra Nevada están poco marcadas); endóstoma de 8 segmentos diversamente desarrollados (en los ejemplares de Sierra Nevada, está reducido a segmentos vestigiales o cortos, uniseriados en el ápice)(Fig. 2.)

En el Sistema Central, se encontró en rocas verticales, graníticas y gneísicas húmedas, cerca de lugares por donde escurre agua del deshielo a una altitud de $2.050 \mathrm{msnm}$. En Sierra Nevada, donde la especie tiene su localidad más meridional en Europa, se ha encontrado sobre micaesquistos cuarcíticos, en fisuras de rocas verticales, poco accesibles, en lugares muy sombríos de la cara noroeste de los Peñones de San Francisco, a una altitud de $2.500 \mathrm{msnm}$.

Este taxón viene a engrosar el numeroso listado de briófitos ártico-alpinos, aislados como taxones relictos, en los lugares más elevados de Sierra Nevada, entre ellos podemos citar: Anthelia juratzkana (Limpr.) Trevis., Asterella gracilis (F. Weber) Underw., Bryum schleicheri Schwägr., Diplophyllum taxifolium (Wahlenb.) Dumort., Eurhynchiastrum diversifolium (Schimp.) J. Guerra, Hygrohypnum molle (Hedw.) Loeske, Hymenoloma mulahaceni (Höhn.) Ochyra, Lescuraea radicosa (Mitt.) Mönk., Mesoptychia heterocolpos (Thed. ex Hartm.) L. Söderstr. \& Váňa, Pohlia bolanderi (Lesq.) Broth., Schistidium agassizii Sull. \& Lesq., Schistidium occidentale (E. Lawton) S.P. Curchill, Syntrichia norvegica F. Weber., etc.

\section{Agradecimientos}

Este trabajo se ha realizado en el marco del Proyecto CGL2015/64068-P, subvencionado por el MINECO y fondos FEDER de investigación. Agradezco a F. Lara (UAM) la revisión de la muestra. 


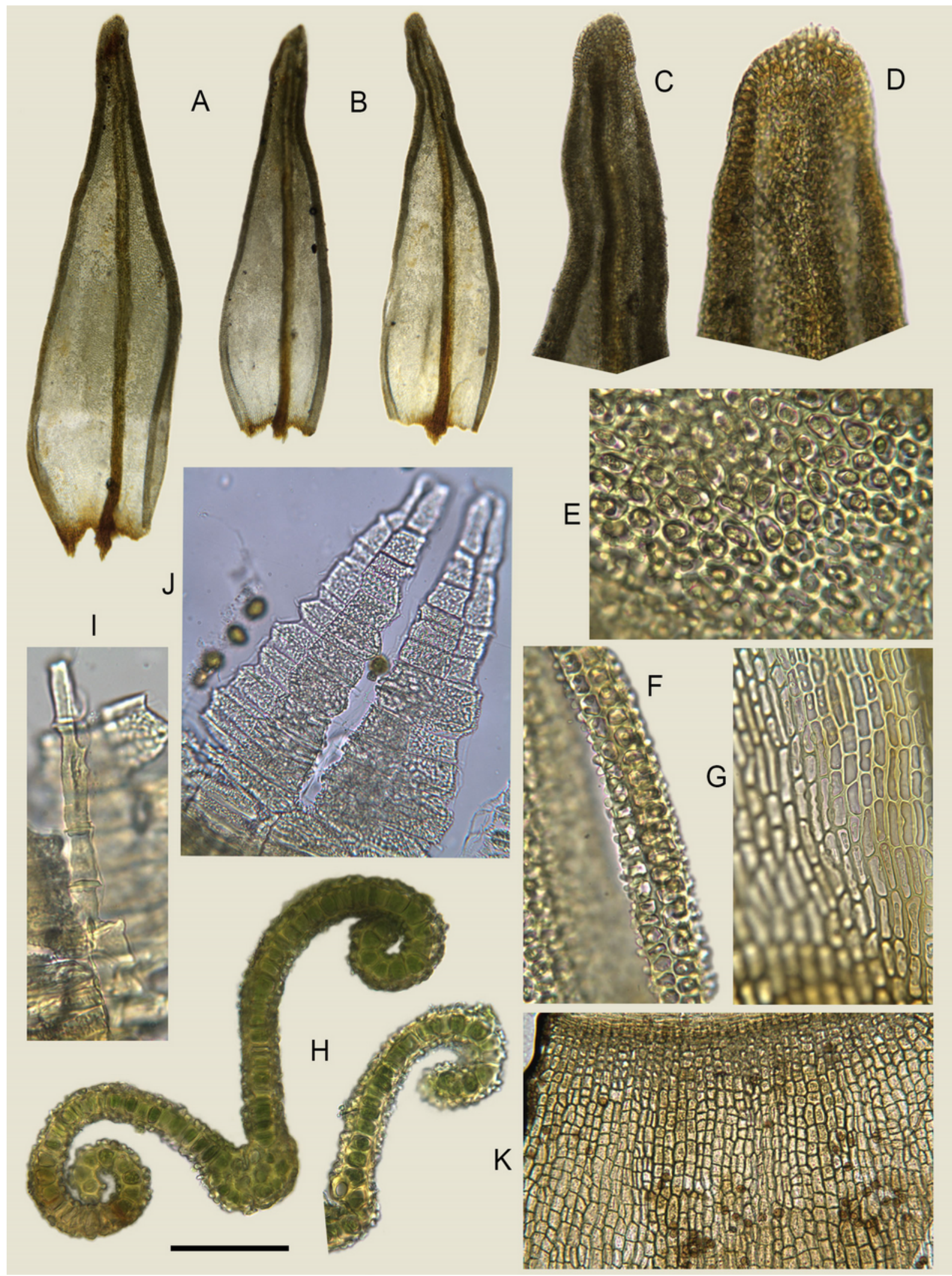

Figura 2. Lewinskya laevigata (MUB 57655). A: Filidio periquecial. B: Filidios vegetativos. C: Ápice de un filidio. D: Detalle del ápice de un filidio. E: Células superiores de la lámina. F: Células marginales de la lámina. G: Células basales de la lámina. H: Secciones transversales de un filidio. I: Segmento del endóstoma. J: Porción del exóstoma. K: Células del exotecio. Barras de escala: A, B= 0,7 mm; $\mathrm{C}=220 \mu \mathrm{m} ; \mathrm{D}=100 \mu \mathrm{m} ; \mathrm{E}=50 \mu \mathrm{m} ; \mathrm{F}, \mathrm{H}=60 \mu \mathrm{m} ; \mathrm{G}=80 \mu \mathrm{m} ; \mathrm{I}=40 \mu \mathrm{m} ; \mathrm{J}=90 \mu \mathrm{m} ; \mathrm{K}=270 \mu \mathrm{m}$.

Figure 2. Lewinskya laevigata (MUB 57655). A: Perichaetial leaf. B: Vegetative leaves. C: Leaf apex. D: Apex leaf detail. E: Upper laminal cells. F: Marginal laminal cells. G: Basal laminal cells. H: Transverse sections of lamina. I: Endostome segment. J: Exostome portion. K: Exothecial cells. Scale bars: A, B= 0,7 mm; C=220 $\mu \mathrm{m} ; \mathrm{D}=100 \mu \mathrm{m} ; \mathrm{E}=50 \mu \mathrm{m} ; \mathrm{F}, \mathrm{H}=60 \mu \mathrm{m} ; \mathrm{G}=80 \mu \mathrm{m} ; \mathrm{I}=40 \mu \mathrm{m} ; \mathrm{J}=90 \mu \mathrm{m} ; \mathrm{K}=270 \mu \mathrm{m}$. 


\section{Referencias}

Blockeel TL. 2010. The bryophytes of Greece: new records and observations, 2. Nova Hedwigia 138: 129-146.

Garilleti R, Albertos B, Puche F, Brugués M \& Lara F. 2014. Orthotrichum laevigatum J.E. Zetterst. New national and regional bryophyte records, 40 . Journal of Bryology 36 (3): 223-244.

Lara F, Garilleti R, Mazimpaka V \& Cortini Pedrotti C. 2002. Confirmation of the identity of Orthotrichum arcangelianum Massari. Journal of Bryology 24: 81-83.
Lara F \& Garilleti R. 2014. Orthotrichum Hedw. En Flora Briofítica Ibérica, vol. V (Guerra J \& Brugués $M$, eds.). Murcia: SEB/UMU, pp. 50-135.

Lara F, Garilleti R, Goffinet B, Draper I, Medina R, Vigalondo B \& Mazimpaka V. 2016. Lewinskya, a new genus to accommodate the phaneroporous and monoicous taxa of Orthotrichum (Bryophyta, Orthotrichaceae). Cryptogamie, Bryologie 37(4): 361-382.

Lewinsky J. 1993. Monographic studies on Orthotrichum (Musci). Bryobrothera 2: 1-59.

Maier E. \& Schäfer-Verwimp A. 1999. Orthotrichum laevigatum Zett. im Wallis. Meylania 17: 21-23. 